\title{
Sazonalidade do preço do leite no Rio Grande do Sul (1986-2009)
}

\author{
Seasonality of milk prices in Rio Grande do Sul (1986-2009)
}

Solange Regina Marin' Ana Gabriela CavalheiroII Daniel AnschauII

\section{- NOTA -}

RESUMO

Objetivou-se calcular os índices sazonais sobre os preços mensais recebidos pelos produtores de leite gaúchos nos anos de 1986 a 2009 e mostrar seu comportamento nos períodos de pré (1986-1994) e pós-estabilização econômica (1995-2009). A hipótese a ser testada, com o uso do método das médias móveis de KAZMIER (1982), é a de que a influência sazonal sobre os preços ao produtor leiteiro no Rio Grande do Sul no período de estabilização econômica difere do período de instabilidade da economia brasileira. Os efeitos sazonais sobre os preços ao produtor de leite gaúcho foram menores no período de estabilidade econômica do que no período de altas taxas de inflação.

Palavras-chave: sazonalidade, preços, leite.

\section{ABSTRACT}

The aim of this note is to calculate seasonality indexes of monthly prices received by dairy farmers in Rio Grande do Sul from 1986 to 2009. Additionally, to show the seasonal indexes for two different periods of Brazilian economy: before economic stabilization (1986-1994) and after economic stabilization (1995-2009). The hypothesis to be tested, with the method proposed by KAZMIER (1982), is the one that the seasonal influence on the prices in the period of economic stabilization differs of the period of high inflation rates of the Brazilian economy. The seasonal effects on monthly prices received by dairy farmers in Rio Grande do Sul were lesser in the period of economic stabilization than in the period of high inflation rates.

Key words: seasonality, prices, milk.
O Estado gaúcho produziu 3.314.573 de litros de leite em 2008 - 12\% da quantidade produzida de leite no Brasil. As mesorregiões maiores produtoras são: Noroeste Rio-Grandense com 64\%, Nordeste RioGrandense com $12 \%$ e Centro Oriental Rio-Grandense com 9\%. Destacam-se as microrregiões de Passo Fundo (12\%), Lajeado-Estrela (7\%), Três Passos (6\%), Erechim (5\%), Frederico Westphalen (5,7\%), Santa Rosa (6\%) e Guaporé (6\%), representando $50 \%$ da produção estadual (IBGE/PAM, 2008).

De todas as cadeias produtivas do setor agropecuário, a que mais se transformou, nos últimos anos, foi a do leite. Para GOMES \& PONCHIO (2005), essas mudanças estruturais foram motivadas pela desregulamentação do mercado em 1991, pela abertura da economia brasileira para o mercado internacional e pela estabilização dos preços com a introdução do Plano Real em julho de 1994.

O setor agropecuário gaúcho não pode ser analisado isoladamente, ou seja, é influenciado pela política econômica brasileira, em especial a integração do Mercosul e a abertura da economia na década de

\footnotetext{
IDepartamento de Ciências Econômicas, Universidade Federal de Santa Maria (UFSM), Rua Floriano Peixoto, 1750, sala 611, Bairro Centro, 97015-372, Santa Maria, RS, Brasil. E-mail:marin@smail.ufsm.br. Autor para correspondência.

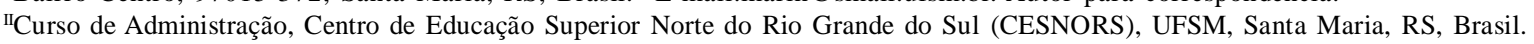
IIICurso de Zootecnia, CESNORS/UFSM, Santa Maria, RS, Brasil.
} 
90, conforme SOUZA (1999). Além disso, o Plano Real aprofundou a falta de proteção do setor primário, adicionando dois elementos prejudiciais a seu funcionamento: a elevação dos juros e a valorização do câmbio.

Ainda no que se refere aos efeitos das políticas econômicas sobre o setor leiteiro, PONCHIO (2005) destaca que a década de 70 apresenta um baixo nível tecnológico e certo "abandono" da atividade leiteira e a década de 80 contou com o intervencionismo do governo, que foi responsável pelo pouco dinamismo produtivo. No ano de 1991, o Estado deixou de regulamentar os preços praticados ao longo da cadeia produtiva; o mercado se encarregou de suprir as demandas da população brasileira bem como de diminuir os custos de produção para o controle da inflação.

A sazonalidade, resultado de causas naturais, econômicas, sociais e institucionais, pode ser definida como o conjunto dos movimentos com período igual ou inferior a um ano, sistemáticos, mas não necessariamente regulares, que ocorrem numa série temporal (QUEIROZ \& CAVALHEIRO, 2003). Como a sazonalidade pode ser resultado de causas econômicas, o objetivo do trabalho foi calcular os efeitos sazonais sobre os preços pagos aos produtores gaúchos de leite no período de 1986 a 2009, com ênfase nos períodos pré e pós-estabilização econômica.

A hipótese a ser testada é a de que a influência sazonal sobre os preços é modificada quando a economia passa a conviver com estabilidade econômica. São calculados os índices sazonais para os períodos de 1986 a 1994 e 1995 a 2009 e comparados de forma a verificar se ocorreram modificações na influência sazonal sobre os preços ao produtor de leite no RS.

Podem ser citados, conforme GOMES (2001), três argumentos para explicar o comportamento sazonal do preço do leite: i) a memória do produtor safrista dá o ambiente para reduzir o preço do leite, nas primeiras trovoadas, ainda que a efetiva produção não tenha aumentado, significativamente; ii) a predominância de sistemas de produção de menor custo no verão, em relação ao do inverno, porque, no período do verão, privilegiam o uso de pastagens e reduzem o consumo de concentrado e iii) as imperfeições do mercado, em nível de indústria, magnificam os efeitos da memória safrista e do menor custo nas águas.
Segundo QUEIROZ \& CAVALHEIRO(2003), a sazonalidade é uma característica frequente na demanda por alimentos e é causada por variações climáticas, datas comemorativas, entre outros fatores. Com isso, é conveniente utilizar procedimentos para avaliá-la e métodos de previsão que considerem o efeito das flutuações sazonais sobre a demanda. Quanto mais informações sobre o comportamento da demanda de um produto, mais acurada será a previsão e, consequentemente, as decisões baseadas nessa previsão. A menor produção é um fundamento importante que pode elevar os preços recebidos pelos produtores, mas o resultado requer ainda a análise da demanda, que pode ser feita a partir dos preços.

A análise da variação estacional de preços torna-se importante, à medida que pode auxiliar o processo de tomada de decisões na produção, comercialização, formulação de políticas agrícolas e de abastecimentos (SÁ \& SILVA,1992). Dada a importância dos efeitos sazonais em produtos agropecuários e as diferentes políticas adotadas na economia brasileira nos anos 80 e 90, que impactaram o setor leiteiro, a estimação dos índices sazonais sobre os preços ao produtor de leite torna-se uma importante ferramenta de planejamento para os produtores gaúchos.

A metodologia baseou-se em uma pesquisa estatística que seguiu duas etapas. Na primeira, foram coletados os preços nominais mensais, recebidos pelos produtores gaúchos na Associação Rio Grandense de Empreendimentos de Assistência Técnica e Extensão Rural (EMATER/RS) para o período de 1986 a 2009. Os preços nominais foram deflacionados pelo índice geral de preços (IGP-di), base em agosto de 1994, obtido no Instituto de Pesquisa Econômica Aplicada (IPEADATA) com base modificada para dezembro de 2009. Na segunda etapa, foi calculado o índice sazonal pelo método das médias móveis, conforme KAZMIER (1982). Esse método consiste em elaborar uma tabela com os valores já calculados da razão à média móvel em percentagem e distribuídos em colunas que representem os anos a serem considerados. Em seguida, é necessário encontrar os valores extremos (máximos e mínimos) a cada mês do ano e cancelá-los, eliminando componentes irregulares da série. Calcula-se então a média móvel modificada dos meses, multiplicando-se por um fator de correção, de tal forma, que a soma das 
doze razões mensais seja mil e duzentos. Tem-se então o índice de sazonalidade mensal dos preços.

A sazonalidade é uma característica frequente nos produtos alimentícios, como é o caso do leite. Entretanto, algumas flutuações nos dados nem sempre caracterizam um movimento sazonal. A aplicação do método de cálculo dos índices sazonais mostra que os preços do leite no Rio Grande do Sul tendem a ser menores nos primeiros seis meses do ano. Portanto, outros fatores, além da influência sazonal, precisam ser considerados. Por exemplo, o excesso de leite no mercado também significa queda nos preços recebidos pelos produtores.

O período de baixa de preços pode ser respondido dentro do $\mathrm{RS}$ como o período de temperaturas elevadas, no qual o consumo de leite pela população é baixo e a disponibilidade de pastagem é maior, causando uma demasiada oferta. O comportamento sazonal do preço do leite deriva também do comportamento sazonal do consumo que tende a ser maior no inverno.

A quantidade de produto ofertado no mercado induz o comportamento dos preços, tanto do produto em si quanto dos insumos necessários para a produção. Por exemplo, se ocorre uma superprodução de leite, o preço do produto tende cair devido à grande oferta. Por isso, é relevante conhecer o comportamento histórico dos preços para projetar como e quanto o setor deverá produzir no futuro.

Com o cálculo baseado nas médias móveis centrais, foi encontrado um índice mensal sobre o preço recebido pelo produtor nos dois períodos: pré e pósestabilização econômica (Tabela 1). Os índices sazonais no período pré-estabilização (1986-1994) indicam a influência sazonal positiva no preço ao produtor de leite, nos meses de junho a dezembro, e negativa, nos meses de janeiro a maio. No período pós-estabilização econômica (1995-2009), os índices mostram efeitos sazonais positivos sobre os preços ao produtor nos meses de junho a novembro. Porém, o fator sazonal influenciou negativamente os preços entre os meses de dezembro a maio.

No período de 1994 a 2009, quando ocorrem os efeitos sazonais negativos, estes são menores do que os verificados para o período de 1986 a 1994. Quando analisadas as variações dos índices mensais entre os diferentes períodos, verificam-se variações positivas de janeiro a junho e negativas de julho a dezembro. Os meses de janeiro $(15,7 \%)$ e fevereiro $(12,15 \%)$ apresentam as maiores variações positivas e os meses de julho $(-10,7 \%)$ e agosto $(-10,94 \%)$ as maiores variações negativas.

Considerando as diferentes estações do ano, é possível notar que, nos meses de verão, apesar de efeitos sazonais negativos, os preços sofreram menores influências sazonais no período pósestabilização econômica. Nos meses de inverno, foram observados efeitos sazonais positivos sobre os preços, porém maiores no período de pré-estabilização da economia. Os preços foram influenciados pelos efeitos sazonais nos dois períodos da economia, mas diferenças maiores entre os meses foram observadas no período de altas taxas de inflação.

Após o Plano Real, os efeitos sazonais ocorreram, porém os índices mensais apresentaram discrepâncias menores. No período de estabilidade, os preços foram impactados de forma mais amena pelos fatores sazonais. Ou seja, a estabilização da economia parece ter sido um dos fatores que colaboraram para efeitos sazonais menores sobre os preços ao produtor de leite gaúcho. A hipótese de que os efeitos sazonais seriam diferentes conforme o período da economia brasileira foi corroborada, ou seja, resistiu frente as observações e a experimentação empírica realizada - o cálculo estatístico dos índices sazonais para os anos de 1986 a 2009.

Tabela 1 - Índice de sazonalidade do preço do leite no Rio Grande do Sul no período pré (1986-1994) e pós (1995-2009) estabilização econômica.

\begin{tabular}{lcccccccccccc}
\hline Período & Jan & Fev & Mar & Abr & Mai & Jun & Jul & Ago & Set & Out & Nov & Dez \\
\hline Pré & 83,1 & 84,8 & 90,7 & 97,0 & 95,0 & 100,1 & 113,8 & 113,7 & 109,7 & 106,0 & 103,4 & 102,3 \\
Pós & 96,1 & 95,1 & 95,8 & 97,3 & 99,7 & 101,4 & 102,8 & 102,5 & 100,5 & 107,4 & 105,5 & 96,0 \\
\hline
\end{tabular}

Fonte: Elaborado pelos autores a partir de dados da Emater/RS. 


\section{REFERÊNCIAS}

GOMES, A.L.; PONCHIO, L.A. A função custo no setor do leite: uma abordagem para a região centro-sul do Brasil. CEPEA/ Esalq-USP, 2005. Disponível em: <http://www.cepea.esalq.usp.br/pdf/ artigo_leite_01.pdf. Acesso em: 15 nov. 2008>.

GOMES, S.T. Evolução e perspectivas da produção de leite no Brasil. In: GOMES A.T. O Agronegócio do leite no Brasil. Juiz de Fora: EMBRAPA-CNPGL, 2001. 262p.

IBGE/Produção Agrícola Municipal (PAM). Disponível em: <http://www.ibge.gov.br/home/estatistica/economia/pam/2008/ default.shtm>. Acesso em: 06 out. 2010.

KAZMIER, L. Estatística aplicada a economia e administração. São Paulo: McGraw-Hill do Brasil, 1982. $380 \mathrm{p}$.

PONCHIO, L.A. Exportações lácteas, uma solução para os produtores ou um problema para os consumidores? CEPEA/Esalq-USP, 2005. Disponível em: <http:// www.cepea.esalq.usp.br/pdf/artigo_leite_03.pdf. Acesso em: 06 nov. 2008>.

QUEIROZ, A.A.; CAVALHEIRO, D. Método de previsão de demanda e detecção de sazonalidade para o planejamento da produção de indústrias de alimentos. In: ENCONTRO NACIONAL DE ENGENHARIA DA PRODUÇÃO, 2003, Ouro Preto, MG. Anais... Disponível em: <http://www.abepro.org.br/ biblioteca/ENEGEP2003_TR0101_0801.pdf>. Acesso em: 02 nov. 2008 .

SÁ, J.M.; SILVA, R.P. Variação estacional e comparação de padrões de variação estacional de preços de arroz, feijão, milho e boi gordo, em Goiás, no período de 1974-84. Anais da Escola de Agronomia e Veterinária, Universidade Federal de Goiás, Goiânia, v.1-22, p.61-92, 1992. Disponível em: http:/ /www.revistas.ufg.br/index.php/pat/article/viewFile/2604/2586. Acesso em: 26 out. 2008.

SOUZA, O.T. O setor leiteiro: política, competitividade e impactos de liberalização comercial nos anos noventa. 1999. 130f. Dissertação (Mestrado em Desenvolvimento Rural) - Curso de Pós-graduação em Desenvolvimento Rural - PGDR, Universidade Federal do Rio Grande do Sul. 